\title{
X-Ray Absorption Spectra and the Local Structure of Nickel in Some Oxycompounds and Fluorides
}

\author{
A.N. Mansour and C.A. Melendres* \\ Naval Surface Warfare Center, Carderock Division, Code 684, 10901 New Hampshire Avenue, \\ Silver Spring, MD 20903-5640, U.S.A. \\ * Argonne National Laboratory, Materials Science and Chemical Technology Divisions, \\ 9700 South Cass Avenue, Argonne, IL 60439-8111, U.S.A.
}

\begin{abstract}
X-ray absorption spectra were measured for a number of nickel oxycompounds and fluorides which contain nickel with valencies in the range of 2 to 4 . Information on the local structure and nature of bonding of nickel were derived using theoretical standards generated with the FEFF code. The energies of the main Ni K-edge and the pre-edge peak were found to shift to higher values by about 1.5 and $0.6 \mathrm{eV}$, respectively, per unit increase in the valency of nickel. The average $\mathrm{Ni}-\mathrm{O}$ and $\mathrm{Ni}-\mathrm{F}$ bond length within the octahedron decreased linearly with increase in nickel valency from 2 to 4 . The local structure parameters for the higher valency nickel oxycompounds are consistent with a multi-phase model in which up to three phases corresponding to $\mathrm{Ni}^{2+}, \mathrm{Ni}^{3+}$, and $\mathrm{Ni}^{4+}$ could be present in different proportions depending on preparation procedures.
\end{abstract}

\section{INTRODUCTION}

The structure and composition of the higher oxide forms of nickel where nickel has a valency greater than 2 are of great interest from the standpoint of developing materials for energy conversion and storage devices (e.g., advanced nickel batteries, fuel cells, and supercapacitors) as well as understanding the comosion-passivation behavior of nickel and its alloys in aqueous solution environments. The various phases that are formed during the charging and discharging of the nickel oxide electrode (NOE) have been the subject of extensive studies since the Edison cell was invented about 100 years ago.[1] While there seems to be a general agreement that the divalent oxide and hydroxide forms of nickel could be well represented by the stoichiometric formulae $\mathrm{NiO}$ and $\mathrm{Ni}(\mathrm{OH})_{2}(\alpha$ and $\beta$ modifications), respectively, various formulations of trivalent nickel oxides and hydroxides have been given in the literature. Thus, stoichiometric formulae like $\beta$ - and $\gamma-\mathrm{NiOOH}, \mathrm{Ni}_{2} \mathrm{O}_{3}, \mathrm{Ni}_{3} \mathrm{O}_{4}, \mathrm{Ni}_{3} \mathrm{O}_{2}(\mathrm{OH})_{4}$ have been proposed. A quadrivalent form, $\mathrm{NiO}_{2}$, has also been claimed amid much controversy. The confusion stems mainly from the highly disordered or amorphous nature of the phases formed which makes structural determination by $x$-ray diffraction difficult. X-ray absorption spectroscopy (XAS) is uniquely suited for studying the local structure of such materials and have been used to characterize the structure of the NOE. McBreen et al.[2] carried out XAS studies in situ in electrochemical cells during the charging and discharging cycles. Capehart et al.,[3] using thin films of $\mathrm{Ni}(\mathrm{OH})_{2}$, claimed to have charged the nickel electrode to a state where the average nickel valency was 3.67 and thus postulating the formation of $\mathrm{a} \mathrm{K}\left(\mathrm{NiO}_{2}\right)_{3}$ phase. Our objective was to determine if simple relationships exist between (i) the Ni x-ray absorption edge energy and valency of nickel and (ii) the $\mathrm{Ni}-\mathrm{O}$ and $\mathrm{Ni}-\mathrm{F}$ bond lengths and the valency of nickel. Subsequently, this information will be used to aid in the determination of the valency of nickel in various oxyhydroxides and electrochemically formed nickel phases. Therefore, we have measured and analyzed the x-ray absorption spectra of structurally well defined nickel oxides, hydroxides, and fluorides such as $\mathrm{NiO}, \beta-\mathrm{Ni}(\mathrm{OH})_{2}, \mathrm{LiNiO}_{2}, \mathrm{KNiIO}_{6}, \mathrm{NiF}_{2}, \mathrm{~K}_{3} \mathrm{NiF}_{6}$, and $\mathrm{K}_{2} \mathrm{NiF}_{6}$ as well as other compounds such as $\alpha-\mathrm{Ni}(\mathrm{OH})_{2}$, $\mathrm{Ni}_{2} \mathrm{O}_{3} \cdot 6 \mathrm{H}_{2} \mathrm{O}, \mathrm{Ni}_{3} \mathrm{O}_{2}(\mathrm{OH})_{4}, \mathrm{NiO}_{2}, \beta$ - and $\gamma-\mathrm{NiOOH}$ whose structures are not as well established.

\section{EXPERIMENTAL}

Most of the compounds studied were prepared by chemical synthesis following procedures established in the literature; others were purchased from commercial suppliers. [4] Three samples of $\gamma-\mathrm{NiOOH}$ were prepared following the procedures described by Bartl et al.,[5] Cotton and Wilkinson, [6] and Capehart et al.[3]; they will be referred to hereafter as $\gamma-\mathrm{NiOOH}(1), \gamma-\mathrm{NiOOH}(2)$, and $\gamma$ NiOOH (3), respectively. The X-ray absorption experiments were performed on beamline X-11A of the National Synchrotron Light Source (NSLS) at Brookhaven National Laboratory (BNL) with the electron storage ring operating at an electron energy of $2.5 \mathrm{GeV}$ and a stored current in the range of 110 to $220 \mathrm{~mA}$. Spectra of the Ni K-edge $(8333 \mathrm{eV})$ were obtained in the transmission mode at room temperature $(300 \mathrm{~K})$. The energy calibration of the monochromator was monitored using a Ni foil employing a third ion chamber. To minimize the effect of particle size on EXAFS amplitudes, powdered samples were prepared by grinding and sieving through a 20- $\mu \mathrm{m}$-size nylon screen. The sieved powder was then spread on Kapton tape or mixed with BN and pressed into pellets. The $\mathrm{x}$-ray absorption edge jump for each sample was kept below 1.5 in order to minimize the thickness effect. 


\section{RESULTS}

The Ni K-edge absorption and the EXAFS spectra were extracted from the raw data using procedures described elsewhere.[7] Local structure parameters were obtained using ab initio theoretical backscattering amplitude and phase values based on the curve-wave single scattering formalism. These were generated with the FEFF Code[8] employing $x$-ray diffraction structural data for NiO and/or $\beta-\mathrm{Ni}(\mathrm{OH})_{2}$. As expected, the $\mathrm{Ni} \mathrm{K}$-edge shifted to higher energies as the oxidation state increased from $\mathrm{Ni}^{0}$ (metallic $\mathrm{Ni}$ ), to $\mathrm{Ni}^{2+}$ $\left(\mathrm{NiO}, \mathrm{Ni}(\mathrm{OH})_{2}\right.$ or $\left.\mathrm{NiF}_{2}\right)$ and $\mathrm{Ni}^{4+}\left(\mathrm{KNiIO}_{6}\right.$ or $\left.\mathrm{K}_{2} \mathrm{NiF}_{6}\right)$. Variations in the $\mathrm{Ni} \mathrm{K}$-edge energy (measured as the energy at which the normalized absorption intensity is equal to 0.5 ) as a function of nickel valency are shown in Figure $1 \mathrm{a}$. It shows that the nickel $\mathrm{K}$-edge energy shifts by $1.5 \mathrm{eV}$ per unit change in valency of nickel. The pre-edge peak energy which corresponds to the transition from the is core level to bound unoccupied states near the Fermi level also shifts to higher energy with increase in nickel valency. Variations in the pre-edge peak energy (measured as the energy at which the absorption intensity is half the pre-edge peak intensity) as a function of valency of nickel are shown in Figure $1 \mathrm{~b}$ which shows a shift of $0.6 \mathrm{eV}$ per unit change in valency of nickel. Based on these results, the $\mathrm{x}$-ray absorption edge energies for other compounds indicate that the average valency of nickel increases in the order $\mathrm{NiO}_{2}<\mathrm{NiO}_{2}$ $=\mathrm{Ni}_{2} \mathrm{O}_{3} \cdot 6 \mathrm{H}_{2} \mathrm{O}<\gamma-\mathrm{NiOOH}(3)<\beta-\mathrm{NiOOH}=\mathrm{Ni}_{3} \mathrm{O}_{2}(\mathrm{OH})_{4}=\gamma-\mathrm{NiOOH}(3)<\gamma-\mathrm{NiOOH}(2)<\mathrm{KNilO}_{6}$. Results of local structure analysis indicate that the $\mathrm{Ni}-\mathrm{O}$ bond length for divalent nickel with an octahedral coordination is in the range of 2.06 to $2.08 \AA$. The structure of the first coordination sphere for $\mathrm{LiNiO}_{2}$ consists of a distorted octahedron with 4 oxygens at $1.91 \AA$ and two oxygens at $2.06 \AA$ rather than 6 oxygens at $2.04 \AA$ as predicted by the $\mathrm{x}$-ray diffraction data. The Ni-O bond length for quadrivalent $\mathrm{Ni}$ in $\mathrm{KNiIO}$ is $1.88 \AA$. Variations in the average Ni-O (for oxides) and Ni-F (for fluorides) first shell distance as a function of nickel valency are shown in Figure le indicating that the first shell distance is inversely proportional to nickel valency in the range of 2 to 4 . Local structure results for the higher valency nickel oxycompounds reveal that the first coordination sphere consists of two different $\mathrm{Ni}-\mathrm{O}$ bond lengths. One $\mathrm{Ni}-\mathrm{O}$ bond length near $1.90 \mathrm{Ả}$ is similar to that for $\mathrm{Ni}^{4+}$ or the short distance for $\mathrm{Ni}^{3+}$ in $\mathrm{LiNiO}_{2}$. The other $\mathrm{Ni}-\mathrm{O}$ bond length near $2.07 \AA \AA$ is similar to that for $\mathrm{Ni}^{2+}$ or the long distance for $\mathrm{Ni}^{3+}$ in $\mathrm{LiNiO}_{2}$. The distribution of these $\mathrm{Ni}-\mathrm{O}$ bond lengths varies from sample to sample and in some cases differs significantly from that observed for $\mathrm{LiNiO}_{2}$ (i.e., 4 short and 2 long distances). The $x$-ray absorption edge energies and local structure results suggest that the higher valency nickel oxycompounds may consist of up to three phases corresponding to $\mathrm{Ni}^{4+}, \mathrm{Ni}^{3+}$, and $\mathrm{Ni}^{2+}$ in different proportions depending on preparation procedures.
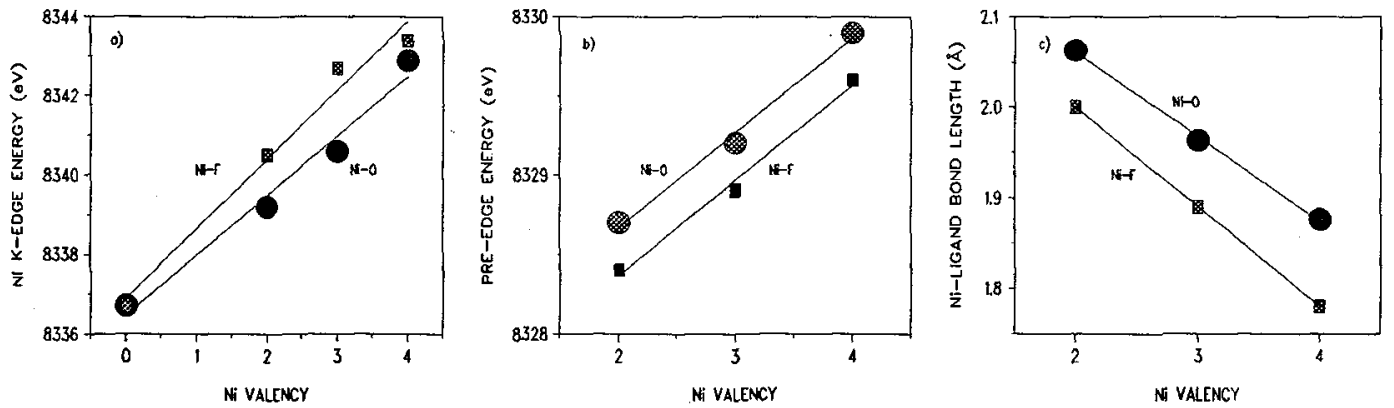

Figure 1: Ni K-edge energy (a), pre-edge peak energy (b), and the average Ni-Ligand bond length(Ni-O for oxides and Ni-F for fluorides) as a function of Ni Valency obtained from structurally well defined nickel oxides and fluorides.

\section{Acknowledgments}

The authors acknowledge financial support from ONR under contract \# N0001496WX20162 and the NSWCCD ILIR Program (ANM) and the U.S. DOE (CAM). The support of the U.S. DOE under contract number DE-AS05-80-ER-10742 for its role in the development and operation of beam line X-11A at the NSLS is also acknowledged. The NSLS is supported by the U.S. DOE, Division of Materials Sciences and Division of Chemical Sciences, under contract number DE-AC02-76CH00016.

\section{References}

[1] Oliva P., Leonardi J., Laurent J.F,, Delmas C., Braconier J. J., Figlarz M., Fievet M., and de Guibert A., J. Power Sources 8 (1982) 229

[2] McBreen J., O'Grady W.E., Pandya K.I., Hoffman R.W., and Sayers D.E, Langmuir 3 (1987) 931.

[3] Capehart T.W., Corrigan D.A., Conell R.S., Pandya K.I., and Hoffman R. W., Appl. Phys. Lett. 58 (1991) 865.

[4] Mansour A.N. and Melendres C.A., Physica B 208 \& 209 (1995) 583.

[5] Bartl H., Bode H., Sterr G., and Witte J., Electrochim Acta, 16 (1971) 615.

[6] Cotton F. A. and Wilkinson G., Advanced Inorganic Chemistry (Interscience Publishers, NY, 1966) pp. 891.

[7] Mansour A. N. and Melendres C. A., submitted to J. Phys. Chem. (1996).

[8] Rehr J.J., Mustre de Leon J., Zabinsky S.I., and Albers R.C., J. Am. Chem. Soc. 113 (1991) 5136. 